\title{
DOI 10.35381/cm.v7i3.571
}

\section{Daños a pacientes COVID-19 por infecciones asociadas a la atención en salud y la responsabilidad}

\section{Harm to COVID-19 patients from infections associated with health care and responsability}

\author{
Hernán Santiago Segarra-Cevallos \\ hernan.segarra.17@est.ucacue.edu.ec \\ Universidad Católica de Cuenca, Cuenca \\ Ecuador \\ https://orcid.org/0000-0002-8245-2961 \\ María Auxiliadora Santacruz-Vélez \\ maria.santacruz@ucacue.edu.ec \\ Universidad Católica de Cuenca, Cuenca \\ Ecuador \\ https://orcid.org/0000-0001-9617-7289 \\ Eduardo Xavier León-Micheli \\ eduardo.leonm@ucacue.edu.ec \\ Universidad Católica de Cuenca, Cuenca \\ Ecuador \\ https://orcid.org/0000-0001-5792-099X \\ Marcelo Jorge López-Mesa \\ marcelo.lopez@ucacue.edu.ec \\ Universidad Católica de Cuenca, Cuenca \\ Ecuador \\ https://orcid.org/0000-0002-9158-5184
}

Recibido: 15 de agosto de 2021

Aprobado: 15 de noviembre de 2021 
Hernán Santiago Segarra-Cevallos; María Auxiliadora Santacruz-Vélez; Eduardo Xavier León-Micheli;

\title{
RESUMEN
}

Del análisis de la problemática de salud que representa las Infecciones asociadas a la atención en salud (IAAS) en los hospitales en el Ecuador, y su incidencia en la mortalidad en los pacientes con diagnóstico de COVID 19, se tendrá como objeto de estudio, cuáles son los eximente de responsabilidad en los actos de salud, dentro de ellos los hechos externos y por fuerza mayor, cuando un paciente, que en un inicio aquejo a su ingreso hospitalario un diagnóstico de COVID 19, sin embargo en su evolución también es diagnosticado de sufrir una IAAS, que pudiera estar en relación o no a los cuidados de la salud.

Descriptores: Política de la salud; lucha contra las enfermedades; ciencia y sociedad. (Tomado del tesauro de la UNESCO).

\begin{abstract}
From the analysis of the health problem represented by Infections associated with health care (HAI) in hospitals in Ecuador, and its incidence in mortality in patients diagnosed with COVID 19, the object of study will be which They are the exemptions of responsibility in the health acts within them the external events and by force majeure, when a patient, who initially suffered a diagnosis of COVID 19 at his hospital admission, however in his evolution is also diagnosed of suffering an IAAS, which may or may not be related to health care.
\end{abstract}

Descriptors: Health policy; disease control; science and society. (Taken from the UNESCO thesaurus). 


\section{INTRODUCCIÓN}

El hecho de que la salud de una persona se vea quebrantada en alguna etapa de su vida por situación o evento externo, conlleva a que esta acuda a los servicios de salud; donde por el sólo hecho de asistir a los mismos, representa recibir la atención por parte del personal de salud. Por lo tanto, las infecciones Asociadas a los cuidados de la salud (IAAS) son infecciones localizadas o sistémicas que se producen al estar presente patógeno(s) infeccioso(s) o toxina(s) sin que se haya evidenciado su existencia al momento del ingreso en la unidad de salud, cuyas manifestaciones son evidentes a las 48 horas posteriores (Unahalekhaka, 2011).

En el año 2019 en la ciudad de Wuhan, capital de la provincia de Hubei, en la China central, tuvo origen la nueva pandemia, la "COVID-19 (coronavirus disease 2019) también conocida como enfermedad por nuevo coronavirus, es causada por el coronavirus 2 del síndrome respiratorio agudo severo (SARS-CoV- 2)"(Barroso Peña et al., 2020), que ha cobrado la vida de aproximadamente "4.112.538" (OPS, 2021) personas alrededor del mundo, estas muertes son el producto de las diferentes complicaciones que pueden presentar al infectarse por el virus del COVID 19, y sumado a ello otras enfermedades que pueden sobreañadirse, lo que aumenta la incidencia de muertes

El personal de salud ante esta preocupante situación y realidad de que pacientes en los diferentes hospitales presentan ingresos con sintomatología de COVID 19, y que por la falta de insumos, equipos de bioseguridad, falta de infraestructuras adecuadas, colapso de los sistemas se salud, etc., se ven expuestos a que los casos por infecciones asociadas a atención de salud (IAAS) afecten de manera significativa a estos pacientes infectados por COVID 19, lo que se traduce en mayor incidencia y casos de mortalidad, que trae consigo el riesgo de que se presuma responsabilidades por actos de salud. Por 
lo que este trabajo se enfoca en analizar cuáles serían los eximentes de responsabilidad del personal de salud antes estas situaciones.

\section{Referencial Teórico}

En el Estado ecuatoriano, a finales del 2001, se conformó un sistema de vigilancia epidemiológico que tiene el fin recolectar, analizar e implementar acciones que permitan "planificar y evaluar el impacto de intervenciones" (Ministerio Salud Publica, 2014) y de esta manera poder obtener mejores respuestas ante la presencia de efectos que pongan en riesgo la salud en el territorio ecuatoriano, al cual se denomina Sistema Integrado de Vigilancia Epidemiológica (SIVE). Como datos para la mejor comprensión de lo que se vive en relación a las IAAS, se debe decir que:

En países desarrollados, entre el 5 y $10 \%$ de los pacientes contrae una o más infecciones y se considera que entre el 15 y el $40 \%$ de los pacientes internados en atención crítica resultan afectados1. En entornos de bajos recursos, las tasas de infección pueden superar el $20 \% 2$, pero los datos disponibles son insuficientes para evaluar el peso de la enfermedad en los países en vía de desarrollo.(Fierro et al., 2015, p 30)

Es importante denotar que las Infecciones Asociada a la Atención en Salud que con mayor frecuencia se presentan son las que producen Neumonías asociadas a la ventilación mecánica, infecciones del tracto urinario asociadas al cateterismo vesical, bacteremia asociada al uso de cateterismo venoso central, en donde "El 90\% de las IAAS son causadas por bacterias; las más frecuentes son: Staphylococcus aureus (S. aureus), Streptococcus sp., Acinetobacter sp., Staphylococcus coagulasa negativo (S. coagulasa negativo), Pseudomonas aeruginosa, Escherichia coli, Proteus mirabilis, Salmonella sp. y Klebsiella pneumoniae."(Arango Díaz et al., 2018).

La incidencia de las IAAS permite identificar de manera pertinente la calidad y eficacia que brindan los servicios médicos en los diferentes servicios de salud. Por otro lado, la tasa de infección de esta problemática (IAAS) ha sido calculada por la OMS aproximadamente y "considera entre 4,5 y 7,0 c/100 egresos" (Arango Díaz et al., 2018). 
La consecuencia de muerte por IAAS es elevada, y a su vez se suma a esto mayor tiempo de estancias hospitalarias y por ende mayor costo en la atención de este tipo de pacientes.

Por lo que estudios revelan que "Según datos estimados por el National Nosocomial Infection Surveillance System (NNIS), en el año 2002 se produjeron más de 1,7 millones de IAAS y alrededor de 100.000 muertes anuales por esta causa en Estados Unidos" (Maracaibo \& Castellano, 2020). Este virus pertenece a la familia de los coronavirus y sus características hoy conocidas son que lo denominan "coronavirus 2 del síndrome respiratorio agudo severo (SARS-CoV-2), su forma es redonda u ovalada y a menudo polimórfica, tiene un diámetro de 60 a 140 nm" (Barroso Peña et al., 2020), a esto súmese que la sintomatología que presenta en primera instancia es dolor de garganta, tos, cefalea, malestar general y en algunos cuadros puede presentar alzas térmicas, confundiéndose con facilidad con un cuadro de síndrome gripal, pero "En casos graves se caracteriza por producir neumonía, síndrome de dificultad respiratoria aguda, sepsis y choque séptico que conduce a alrededor del $3 \%$ de los infectados a la muerte, aunque la tasa de mortalidad se encuentra en 4,48 \% y sigue ascendiendo". (Barroso Peña et al., 2020). Además, se debe tomar a consideración que "las infecciones nosocomiales son comunes entre los pacientes con COVID-19". (Open et al., 2021).

Como consideración a la seguridad del paciente, debería implementarse en los distintos niveles de atención de salud y primordialmente en los hospitales una cultura seguridad del paciente donde todos los esfuerzo estén dirigidos hacia la prevención y control de infecciones, en especial a las que hoy en día son consideradas inevitables como las IAAS, aunque se plantee una paradoja, ya que "Los proveedores de atención médica luchan permanentemente por proteger a sus pacientes y no hacer daño, sin embargo la complejidad de las enfermedades y la fragilidad del comportamiento humano muchas veces se traducen en errores o eventos adversos"(Karpenko \& Merkurjev, 2011). 


\section{Revista Interdisciplinaria de Humanidades, Educación, Ciencia y Tecnología \\ Año VII. Vol. VII. N³. Edición Especial III. 2021 \\ Hecho el depósito de ley: pp201602FA4721 \\ ISSN-L: 2542-3029; ISSN: 2610-802X \\ Universidad Nacional Experimental Francisco de Miranda (UNEFM). Santa Ana de Coro. Venezuela}

Hernán Santiago Segarra-Cevallos; María Auxiliadora Santacruz-Vélez; Eduardo Xavier León-Micheli;

Marcelo Jorge López-Mesa

Es por esto que, una las recomendaciones en el transcurso del tiempo ha sido la implementación de una cultura de seguridad del paciente como lo ha venido haciendo la Organización Mundial de la Salud (OMS), cuando "creó en 2004 la Alianza Mundial para la Seguridad del Paciente (2), haciendo énfasis en algunas actividades principales, a saber, en el 2005 y 2006, "una atención limpia es una atención más segura", en el 2007 y 2008, "la cirugía segura salva vidas", en la que se incluye la importancia buena atención, y en el 2008 y 2009, "la lucha contra la resistencia a los antimicrobianos".(Álvarez et al., 2010). Pero también debemos tomar a consideración que "las infecciones nosocomiales son comunes entre los pacientes con COVID-19"

Lo que en ocasiones ocurre a diario en el ámbito hospitalario es que se reporte por parte de las diferentes jefaturas o departamentos donde se mantienen hospitalizados pacientes es que se reporte sobre todo reportes de nuevas infecciones sobre todo en pacientes con larga data de hospitalización, ya sea la aplicación de procedimientos en los cuales se necesita de insumos invasivos como lo son los catéteres venosos centrales, los catéteres vesicales o incluso la más común como es la ventilación mecánica en paciente críticos, como hoy en día lo son los pacientes con insuficiencia respiratoria grave debido al COVID 19. Lo que nos lleva a pensar si dichas nuevas infecciones son producto de acción u omisión que llevan a un daño, recordando que daño es "un perjuicio que sufre una persona o su patrimonio por culpa de otro sujeto. El daño, por lo tanto, supone un detrimento en los derechos, bienes o persona, sea esta físico, moral, intelectual o afectivo, como consecuencia de la acción u omisión de otro" (Minchala, 2015).

Pero para que exista una responsabilidad debe existir un acto antijurídico; pero cuando se han cumplido con todas las normar y procesos con el fin de evitar una infección, la presencia de las mismas no vendría a ser una responsabilidad que deba responder el personal de salud, por lo que diremos que "Las causas eximentes, consisten en aquellas situaciones en que el presunto agente del daño, no está obligado a la reparación es decir, no existe responsabilidad civil, porque no ha realizado ninguna conducta que se 
considere culposa o porque no existe relación de causalidad entre su conducta culposa y el daño sufrido por la víctima" (Minchala, 2015).

Así mismo la relajación en la relación médico paciente hace que el personal de salud tome actitudes y formas ante el devenir de las exigencias de los derechos de paciente, que muchas veces lo que busca es encontrar un error en el actuar médico, más no un remedio o reparo para la dolencia que presenta. También debemos observar que el actuar del médico sea una obligación de medios, más no de resultados, ya que de esta manera podremos constatar su incumplimiento generando así culpabilidad o a su vez un eximente de responsabilidad.

\section{MÉTODO}

\section{Tipo de investigación.}

El presente trabajo es de tipo descriptivo-documental-no experimental-transversal.

\section{Diseño de la investigación.}

El presente trabajo se realizó bajo el tipo de investigación descriptivo debido a que se recogió información relacionada con la temática, además del uso y aplicación de documentos, entre ellos revistas, libros de leyes y medicina que respaldaron y dieron sustento en la medicina basada en evidencia en cuanto a las IAAS, así como artículos que proporcionaron información y datos relacionados con la pandemia del COVID 19 a nivel mundial, eximentes de responsabilidad, entre otros.

Se suma a esta propuesta de trabajo ya que se limitará a observar los acontecimientos sin intervenir en los mismos, así como es de tipo transversal ya que intervendrá en cierto tiempo, el cual estarán relacionado con la pandemia de COVID 19.

\section{Técnicas y procedimientos para la recolección de la información.}




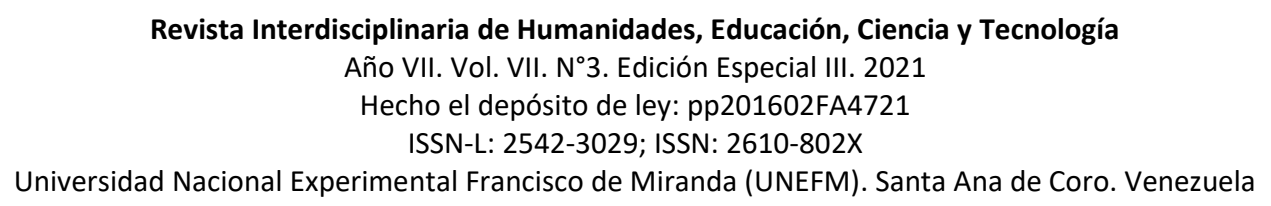

Hernán Santiago Segarra-Cevallos; María Auxiliadora Santacruz-Vélez; Eduardo Xavier León-Micheli;

Marcelo Jorge López-Mesa

En el desarrollo del presente trabajo, se utilizó la técnica de recopilación de datos y documentos, los cuales se analizaron con el fin de formar bases de los eximentes de responsabilidad, ante la presencia de las IAAS dentro del contexto hospitalario, y de esta forma brindar una crítica a los procesos, procedimientos y acciones que se realizan a diario en el cuidado de salud de los pacientes COVID 19.

\section{Instrumentos.}

Los instrumentos a ser utilizados en este trabajo fueron:

Formularios de reporte de IAAS

Formularios de reporte de casos sospechosos y definitivos de COVID 19

Historias Clínicas

Sistemas de Registros de Atención de pacientes tanto físicos como digitales

Páginas y bibliotecas virtuales.

\section{Fuente primaria.}

Las principales fuentes primarias a ser escogidas son:

Pubmed

Mesh

Lilacs

New England journal of medicina

AS400

Tesis

Informes epidemiológicos

\section{Fuente secundaria.}


Las fuentes secundarias que se tomaran en cuenta son: Revistas Médicas

\section{RESULTADOS}

\section{Las Infecciones Asociadas a la Atención de Salud y el COVID-19.}

La humanidad, desde los tiempos antiguos, muestra registros que ponen en manifiesto que las culturas del mundo tenían formadas estructuras que se asemejan a lo que hoy llamamos hospitales, como por ejemplo Grecia, Egipto, Babilonia y la India (Montero et al. 1973), tenían estas estructuras que funcionaban como asilos para personas que viajaban o que presentaban algún tipo de calamidad.

Es por esto que, se podría enfatizar que la humanidad tiene un rastro de interés por los cuidados de la salud de aproximadamente "2.500 años, es decir, desde el siglo V a.C."(Maracaibo \& Castellano, 2020b), siendo importante nombrar algunas épocas donde la importancia por los cuidados de la salud marcaron la historia, como en la era Cristiana (Romanos) donde se fortaleció la creación de hospitales para personas que padecían de enfermedades en auge de esa época; así también tenemos la época de las Cruzadas, en donde sobresalió el cuidado de los heridos de guerra por parte de las Monjas Benedictinas, que formaron órdenes y hermandades que tenían una sola función que era la de sanar dolencias.

Con el avanzar de los años y los conocimientos adquiridos en el tiempo, se fundaron en los diferentes continentes del mundo hospitales, por ejemplo en el continente Americano, "Cortés fundó el Hospital de Jesús en México en 1524, la Institución más antigua de su género en las Américas" (Montero et al., 1973), mientras que los árabes se encargaron de fundar hospitales en España, África del Norte y Asia Menor (Montero et al., 1973). Pero lo que debe llamar la atención es que, en aquellos tiempos la práctica de la medicina tenía como un principio, el de que, cuando una persona presentaba o aquejaba una herida esta debía presentar signos de infección y de los cuales el que más se esperaba 
era el pus, ya que se consideraba que debía estar presente para su cicatrización, lo que hoy en día sería tomado como una negligencia por parte del personal de salud.

Esta práctica llevó a que los hospitales de aquellas épocas se caracterizaran por algo muy peculiar, el olor, que se convertía en hedor, siendo insoportable estar en esas condiciones por lo que como una medida para que tomaron para paliar dicho suceso era "perfumarlos quemando sustancias aromáticas"(Montero et al., 1973), con lo que supusieron mejorar la situación.

Es claro exponer que, en aquellos tiempos, ya se hablaba de que los causantes de estas infecciones era por supuesto microorganismo (bacterias, hongos, etc.) que causaban esta situación, pero es importante señalar que para 1830, un personaje cuya profesión no sólo era la de ser médico y abogado, sino escritor y poeta observó que "la infección en las heridas de sus pacientes se reducía cuando se lavaba las manos en una solución de hipoclorito de calcio entre paciente y paciente" (Montero et al., 1973), este personaje era Oliver Wendell Holmes.

Para 1847 un apóstol (Semmelweis) en Viena, pudo observar que en dos Maternidades ocurría algo muy llamativo, en una de ellas, donde las pacientes eran atendidas por comadronas, presentaban pocas infecciones; a lo contrario de lo que ocurría en las pacientes que eran atendidas por médicos y estudiantes de medicina, en las cuales se presentaban infecciones que llevaban a una mortalidad espeluznante en dicho servicio; y todo aquello según Semmelweis por la falta de lavado de manos, por lo que es obvio donde no se realizaba este procedimiento, hoy protocolizado.

Con el avance de los conocimientos y las medidas de cuidado en la atención de los pacientes, se trató de evitar las infecciones, como lo hizo Pasteur al establecer leyes para la prevención y curación de enfermedades transmisibles; así como Joseph Lister en 1867 "Predicó y practicó la absoluta limpieza y esterilización de instrumentos con ácido carbólico y la atmósfera inmediata con una nebulización carbólica" (Montero et al., 1973) con el fin de que todo lo que entre en contacto con los pacientes tenga antisepsia. 
Seguido a estos parámetros de limpieza se crearon por Alemania otros parámetros para la no existencia de bacterias en cualquier instrumento, insumo o lo que fuere que vaya estar en contacto con alguna parte del cuerpo del paciente, creándose la asepsia.

También se debe nombrar a la enfermera británica Florence Nightingale, que gracias a ella se concibió la organización que tiene nuestros hospitales a día de hoy; esta enfermera predicó lo siguiente "lo primero que no debe hacer un hospital es enfermar" (Maracaibo \& Castellano, 2020b).

Antes de que se diera uno de los descubrimientos más grandes dentro de la ciencia médica como fue el descubrimiento de los antibióticos y antes de la segunda guerra mundial, podría decirse que en esos tiempos "los hospitales eran probablemente más limpios que nunca" (Montero et al., 1973).

Alexander Fleming en 1929, da inicio a la era antibiótica con el descubrimiento de la penicilina con lo que nació una esperanza para ciencia médica en el tratamiento de las infecciones.

En 1936, se dio el descubrimiento de las sulfonamidas que se sumaron a la penicilina y que fueron aplicadas con el fin de tratar las infecciones, pero a su vez deterioro la aplicación de las medidas de limpieza tan necesarias para evitar las mismas. Es por esto que podríamos decir en la actualidad que el uso desmedido de antibióticos, pero más aún el marcado descuido en lo que respecta a la limpieza causa una sanidad deficiente en los hospitales "a pesar del rápido desarrollo de la medicina, la erradicación de las IAAS sigue estando fuera del ámbito de esta" (Maracaibo \& Castellano, 2020b).

Las Infecciones Asociadas a la Atención de Salud (IAAS) en los sistemas de salud representan un problema a considerar por todos los países del mundo, ya que las mismas traducen la morbilidad y mortalidad de dichos sistemas, lo que representa un aumento significativo en los costos al momento de tratar de paliar los efectos negativos que estas infecciones producen no solo en salud, sino a nivel económico y social.

La Organización Mundial de la Salud se refiere a las IAAS como: 
Hernán Santiago Segarra-Cevallos; María Auxiliadora Santacruz-Vélez; Eduardo Xavier León-Micheli; Marcelo Jorge López-Mesa

Las infecciones asociadas a la atención en salud, son las infecciones que se presentan en un paciente internado en un hospital o que ha recibido atención en otro establecimiento de atención de salud, en quien la infección no se había manifestado ni estaba en período de incubación en el momento de la internación. Comprende las infecciones contraídas en el hospital, pero que se presentan después del alta hospitalaria y también las infecciones ocupacionales del personal del establecimiento. (Ministerio de Salud Pública, 2019) Así también existen otras definiciones que con el transcurrir del tiempo y las experiencias aprendidas han tratado de explicar de mejor manera que son las IAAS, e incluso han sido motivo de programas de prevención en salud en hospitales, centros de atención de salud y por parte de personal médico, quienes han llegado a grabar un eslogan "Una atención limpia es una atención más segura"(Organization, 2005).

Las IAAS son consideradas a hoy en día como la causa de efectos no deseados más frecuente tras la asistencia de atención de paciente que aquejan alteraciones en su estado de salud, y que requieren ingreso para su recuperación; es tanto así que "Las IAAS se presentan en un 5 a $10 \%$ de los pacientes que ingresan a una institución de salud"(Maracaibo \& Castellano, 2020a), esta realidad es casi apegada a lo que ocurre en Europa y Norteamérica y no así en los países en vías de desarrollo donde la "infección relacionada con la atención sanitaria es de 2 a 20 veces mayor que en los países desarrollados"(González Cano et al., 2019).

Cabe señalar que las IAAS se ven mayormente relacionadas con ciertos factores que con fines de entendimiento lo dividiremos en 3 grandes grupos a saber: el huésped, el agente infeccioso y el medio ambiente. Dentro de las características que predisponen al huésped a sufrir una IAAS está la edad -recién nacido prematuro y edad avanzada-, y el compromiso del sistema inmunitario de respuesta a enfermedades $-\mathrm{VIH}$, tumores malignos-.

En lo que respecta al agente infeccioso "se hallan las bacterias, virus, hongos y parásitos, estando la mayor parte de las IAAS asociadas a una bacteria o virus" (Mayssara A. Abo 
Hassanin Supervised, 2014) y en lo concerniente al medio ambiente pues tiene que ver con lo animado e inanimado, siendo el factor animado el personal de salud que entra en contacto con el paciente y familiares, mientras que el inanimado recae en los insumos, dispositivos e instrumental que podría utilizarse para el tratamiento del paciente.

Con respecto a este último componente el inanimado podría decirse que las fuentes que se han descrito y que representan el mayor porcentaje de causas de IAAS son las infecciones del tracto respiratorio - "neumonía vinculada al uso de ventilador (NAV)"(Mayssara A. Abo Hassanin Supervised, 2014), las infecciones del tracto urinario - "asociadas al uso de catéter" (Mayssara A. Abo Hassanin Supervised, 2014), las infecciones del sitio quirúrgico y las infecciones del torrente sanguíneo - "relacionada con el uso de catéter"(Mayssara A. Abo Hassanin Supervised, 2014).

\section{El Covid 19 en la humanidad.}

Hacia finales del año 2019, se colocaba con uno de los titulares en cuanto a la aparición de una nueva enfermedad respiratoria de origen desconocido, que producía una neumonía en los pacientes cuyas características y síntomas eran tan agresivos y graves, que llevaron a los pacientes a salas de cuidados intensivos donde tras permanecer algunos días fallecían.

Por esta razón, la mirada del mundo y de las organizaciones y sistemas de salud a nivel mundial se dirigieron a "la ciudad de Wuhan, capital de la provincia de Hubei, en la China central"(García Bacallao, 2020), donde en el mes de diciembre de 2019, trabajadores del mercado mayorista de mariscos del sur de China - Wuhan, presentaron síntomas respiratorios que les ocasionaba una insuficiencia respiratoria grave, por lo que fueron muchos de ellos catalogados como una neumonía de origen desconocido.

Con el pasar de los días, el Comité de Salud Municipal de Wuhan, el 31 de diciembre de 2021 emitió un informe en el que reportaban "por primera vez un grupo de 27 casos similares a la neumonía de etiología desconocida, incluidos 7 casos graves, con un 
Hernán Santiago Segarra-Cevallos; María Auxiliadora Santacruz-Vélez; Eduardo Xavier León-Micheli; Marcelo Jorge López-Mesa

vínculo común informado con el mercado mayorista de mariscos de Huanan en Wuhan"(Tang D, Comish P, 2021).

Con estos antecedentes de la comunidad científica empezó con los estudios pertinentes para dar con el agente causal, es así que se aíslo una nueva cepa de la familia de los coronavirus "que se diferenciaba del SARS-CoV y del MERS-CoV"(Tang D, Comish P, 2021), por lo que en un inicio se lo llamo por parte de la OMS como 2019-nCoV, para posteriormente Ilamarlo "SARS-CoV-2 por el Comité Internacional de Taxonomía de Virus"(Tang \& Comish, 2021), que para mejor entendimiento quiere decir Síndrome Respiratorio Agudo Severo Coronavirus-2 / Severe Acute Respiratory Syndrome Coronavirus-2.

En el continente Asiático, la república de China hace conocer al mundo de que para enero de 2020 en "China se habían reportado 835 casos (534 de Hubei)" (Maguiña Vargas et al., 2020), pero con el pasar de los días esta enfermedad comenzó a expandirse por otros países, pasando luego a otros continentes, por lo que la "la Organización Mundial de la Salud (OMS), declara desde marzo 2020 como una nueva pandemia mundial"(Maguiña Vargas et al., 2020).

Muchos de los esfuerzos por saber de dónde se originó este virus apuntan a que se debe al consumo de animales silvestres dentro de ellos el murciélago y el "pangolín, mamífero usado como alimento"(Maguiña Vargas et al., 2020). En febrero de 2020, la OMS anunció que el nombre de esta nueva enfermedad sería "COVID-19". Con fecha abril de 2021, la Organización Panamericana de Salud (OPS) reporta 130.442.190 casos confirmados de COVID 19 y 2.842.135 muertes (Douedi \& Miskoff, 2020).

El Covid 19 es la enfermedad respiratoria aguda grave, que afecta a la humanidad en estos tiempos y que se transformó en la pandemia del siglo, es la Pandemia del COVID 19 causado por el coronavirus 2 del síndrome respiratorio agudo severo (SARS-CoV-2), el cual es parte de la familia de los coronavirus, los cuales son conocidos ya por la ciencia en que pueden causar enfermedades en animales y humanos, sobre todo en este último 
se conoce que produce enfermedades que afectan al sistema respiratorio, como to ocurrido con el "síndrome respiratorio de Oriente Medio (MERS) y el síndrome respiratorio agudo severo (SRAS)" (García Bacallao, 2020).

Las características que corresponde al virus del COVID 19 son que posee una forma redondeada u ovalada (polimórfica), su diámetro puede variar de 60 a $140 \mathrm{~nm}$, tiene una proteína espiga (glucoproteínas Spike) que se encuentra en la superficie del virus que es lo que le da su imagen como de corona.

El contagio de COVID 19 se da de persona a persona mediante los fómites que pueden expulsarse al toser, hablar o estornudar, recordando que "las gotas respiratorias de más de cinco micras, son capaces de transmitirse a una distancia de hasta dos metros"(Maguiña Vargas et al., 2020).

Es por esto que las medidas de distanciamiento, uso de mascarillas y el lavado de manos con jabón son necesarios para evitar el contagio. Al parecer recientes estudios demuestran que las glucoproteínas Spike tiene una gran afinidad por "los receptores de la enzima convertidora de angiotensina 2 de superficie (ACE2)" (Maguiña Vargas et al., 2020), los mismos que se encuentran predominantemente en el árbol respiratorio e intestinal, he ahí donde radica la presencia de los síntomas que presentan los paciente contagiados por COVID 19.

También es importante destacar que el período de incubación del virus podría ser de 2 a 14 días, pero "el 95\% de los casos fue de 12 días"(Maguiña Vargas et al., 2020). Los pacientes que se contagiaron de COVID 19 en su gran mayoría refirieron estar asintomáticos, pero los que presentaron síntomas estuvieron caracterizados por malestar general y tos leve; pero de esto sintomáticos existieron 2 grupos en el que las manifestaciones clínicas eran evidentes, pues el primer grupo de estos dos representaba el $15 \%$ cuyo cuadro era "moderado con fiebre, tos seca persistente, fatiga, sin neumonía" (Maguiña Vargas et al., 2020); mientras que el segundo grupo correspondía a un 5\% cuyo cuadro era severo y se acompañaba de "fiebre constante, tos, disnea severa, debido 
especialmente a la neumonía viral; daño cardiovascular, falla multiorgánica" (Maguiña Vargas et al., 2020), y sobre todo esto últimos tenían una alta mortalidad.

Los síntomas que generalmente refieren los pacientes que se han contagiado con el virus del COVID 19 son fiebre, tos, disfagia, disnea, mialgias y fatiga, pero en algunos casos hacen referencia a la presencia de anosmia, que es la falta de olfato y ageusia en menor proporción, que es la falta del sentido del gusto.

Pero en los casos graves estos síntomas se exacerban y llevan a los pacientes a sufrir un cuadro de "neumonía, síndrome de dificultad respiratoria aguda, sepsis y choque séptico que conduce a alrededor del $3 \%$ de los infectados a la muerte"(García Bacallao, 2020).

\section{La responsabilidad por actos de salud en el Ecuador}

En Ecuador, muchos tratadistas de orden jurídico comentan sobre la responsabilidad iniciando la mayoría de ellos con paradigmas como es el Código de Hammurabi (17391685 a.c.) donde se recoge un tipo complejo de ley retributiva tras la observación de un daño.

Así mismo, se puede hacer referencia a otras culturas donde se trató de imponer leyes, con el afán de dar un sentido a la responsabilidad por los actos médicos, como la del antiguo Egipto que se refleja en su conocido Libro Sagrado, que indica que las "normas debían cumplirse estrictamente, so pena de muerte para el médico" (Guerrero, 2020) y como dejar de lado a la cultura Romana en el tema de responsabilidad médica, ya que con su Codex Visigothorum - Derecho Romano postclásico, colocaba al "médico negligente o incompetente a la entera disposición de la familia del paciente muerto para que lo matase o redujese a la esclavitud" (Guerrero, 2020).

Sin embargo, en la Edad Media cuyas particularidades hacían denote de religiosidad, hizo de las normas escritas un simple y mero hecho de naturalidad, es decir estas normas estaban dadas por una deidad superior, por lo que se entendía que el "médico era un ser a quien no se le podía imputar responsabilidad alguna en su accionar, teniendo como 
única obligación el intentar curar al paciente, sin que sea necesario acudir a las prácticas comunes y probadas de la medicina" (Guerrero, 2020). No es, sino hasta mediados del siglo XX que, por connotaciones mundiales, como fueron los experimentos médicos nazis de Núremberg, que dejaron perplejos a todo el mundo y los avances en la tecnología del día de hoy, que nuevamente se volvió a controlar con normativa escrita la responsabilidad por actos de salud.

Es por esto que se le ha considerado a la responsabilidad como una obligación que debe realizarse, motivada ésta por la acción que causa alguna situación específica contra terceros, es por eso que algunos estudiosos de los actos de salud han dado conceptos que van desde que "La responsabilidad es la Obligación de reparar y satisfacer por uno mismo, en ocasiones especiales, por otro, la pérdida causada, el mal inferido o el daño originado" (Palacios, 2014), concepto referido por Guillermo Cabanellas de Torres; otro concepto por nombrarlo es "La responsabilidad médica es la obligación para los médicos de sufrir las consecuencias de ciertas faltas por ellos cometidas que pueden comportar una doble acción, civil y penal" (Ordoñez, 2005) esto lo refirió Lacassagne en una cita de Andrés Ycaza Palacios. Y así, se pudiera seguir citando múltiples conceptos sobre lo que se trata de englobar y generalizar el concepto de responsabilidad en actos de salud.

Con estos antecedentes, es importante conocer desde un inicio que responsabilidad se deriva del latín responsum que significa responderé, es decir, es estar obligado, y para mejor entendimiento "es la obligación de satisfacer cualquier daño o perjuicio" (García, 2010).

La medicina como tal, es la ciencia que se encarga de curación, diagnóstico, tratamiento, prevención de las enfermedades y problemas de salud que presentan los seres humanos en el transcurso de su vida, por lo que por su misma naturaleza se ve vinculada a la ciencia del Derecho, esto porque las Leyes protegen a la vida y la salud, y cualquier acto inadecuado que pusiera en riesgo o dañara a cualquiera de ellas trae consigo un juicio de responsabilidad. 
Ahora bien, no está por demás comprender de lo que se considera como acto médico, por lo que recopilo lo que indica el profesor Andrés Esteban Jaimes (2021) en su obra Tratado de Responsabilidad Estatal por Actos de Salud respecto a este tema y el cual expresa que un acto médico es "una modalidad de actuación en el servicio de salud, que se materializa por la relación directa entre el profesional de la medicina y el paciente, basada en el conocimiento de la lex artis, lex artis ad hoc y el respeto" (p. 65) y que todos estos actos están actos están legislados por leyes, códigos, reglamentos, manuales, protocolos y cuya inobservancia puede acarrear una responsabilidad en temas que pueden ir desde lo administrativo, civil y hasta lo penal.

Hablar de responsabilidad por actos de salud tiene un tinte algo complejo, ya que la misma puede considerarse en un marco por Derecho Punitivo o por Derecho de daños, estos dos caminos a su vez tienen aristas que nos pueden llevar en el caso del Derecho Punitivo a configurar una responsabilidad de tipo ético-disciplinaria como primera arista o una responsabilidad de tipo penal como segunda arista. En cambio, en el caso del Derecho de Daños puede configurarse una responsabilidad Estatal o una responsabilidad de tipo civil.

La finalidad de declarar responsabilidad por cualquiera de estas dos vías, en el caso punitivo es la de imponer una sanción, mientras que en la de derecho de daños es la reparación patrimonial de manera pecuniaria o no pecuniaria. Al presente, el personal de salud cuando realiza un acto de salud tiene una obligación de medio con el paciente, es decir se compromete, en que su actuar al brindar la atención será de una manera diligente, con pericia y prudencia y de mostrando que se prestó los medios suficientes en lo que respecta a la capacitación profesional del personal médico, además que el servicio para su recuperación fue el apropiado y que el tratamiento propuesto fue el indicado, denotando que las consecuencias son de medios y no de resultados; pero cuando esto no sucede, se configura la imagen de la responsabilidad por actos de salud. 
Hernán Santiago Segarra-Cevallos; María Auxiliadora Santacruz-Vélez; Eduardo Xavier León-Micheli; Marcelo Jorge López-Mesa

Para cuando se plantea un juicio por responsabilidad se debe tener en cuenta que deben estar presentes los siguientes requisitos, que no deben faltar, caso contrario no se podría hablar de un caso de responsabilidad por actos de salud, "falla presunta, nexo y daño son los elementos que integran la responsabilidad médica" (García, 2010).

La Constitución de la República del Ecuador, podría decirse, es una norma jurídica suprema joven en Latinoamérica ya que su última revisión, publicación oficial y vigente es del año 2008, la cual reemplazó a la anterior Constitución de 1998. Esta norma posee algunos artículos que se encuentran en común relación con los deberes y responsabilidades por actos de salud, así citaremos algunos de ellos para un mejor entender. Se iniciará con lo referente a deberes primordiales del Estado, donde se garantiza el goce del derecho a la salud: Art. 3.- Son deberes primordiales del Estado:

1. Garantizar sin discriminación alguna el efectivo goce de los derechos establecidos en la Constitución y en los instrumentos internacionales, en particular la educación, la salud, la alimentación, la seguridad social y el agua para sus habitantes. (Constitución Política, artículo 3)

De la misma manera, en el siguiente artículo la Constitución del Estado garantiza el derecho de la salud a todas las personas esto mediante la prestación de servicios de salud, medidas económicas, políticas, siempre bajo los principios éticos del cual en este sentido se destaca la responsabilidad.

Art. 32.- La salud es un derecho que garantiza el Estado, cuya realización se vincula al ejercicio de otros derechos, entre ellos el derecho al agua, la alimentación, la educación, la cultura física, el trabajo, la seguridad social, los ambientes sanos y otros que sustentan el buen vivir.

El Estado garantizará este derecho mediante políticas económicas, sociales, culturales, educativas y ambientales; y el acceso permanente, oportuno y sin exclusión a programas, acciones y servicios de promoción y atención integral de salud, salud sexual y salud reproductiva. La prestación de los servicios de salud se regirá por los principios de 
equidad, universalidad, solidaridad, interculturalidad, calidad, eficiencia, eficacia, precaución y bioética, con enfoque de género y generacional. (Constitución Política, artículo 32)

Siguiendo el precepto anteriormente citado, se une un artículo que nos indica que para dar garantía a este derecho que es la salud, existe otro derecho que debe cumplirse que es disponer de servicios de óptima calidad y sobre todo deja en claro que lo único que justifica la vulneración de estos derechos tácitos en el Art. 52, es el caso fortuito o fuerza mayor.

Art. 52.- Las personas tienen derecho a disponer de bienes y servicios de óptima calidad y a elegirlos con libertad, así como a una información precisa y no engañosa sobre su contenido y características.

La ley establecerá los mecanismos de control de calidad y los procedimientos de defensa de las consumidoras y consumidores; y las sanciones por vulneración de estos derechos, la reparación e indemnización por deficiencias, daños o mala calidad de bienes y servicios, y por la interrupción de los servicios públicos que no fuera ocasionada por caso fortuito o fuerza mayor. (Constitución Política, artículo 52)

Quizá uno de los artículos más llamativos en el contexto de la responsabilidad por actos de salud y que es de interés comprenderlo, además de tenerlo en cuenta todo el tiempo, y que habla sobre la generación de responsabilidad civil y penal, siempre que exista una prestación de servicios deficiente sea estas pública o privada, es el Art. 54 que está dirigido para personas o entidades.

En fin, existen otros artículos dentro de la constitución como los Art. 66 - 1,2,3; Art. 83 12; Art. 85 -1; Art. 358, Art. 359, Art. 362, Art 363, Art. 424, Art. 425, los cuales dan luces sobre los derechos, obligaciones, responsabilidades, acciones y prohibiciones que giran en torno a los actos de salud y sus posibles responsabilidades en casos de ir en contra de lo estipulado en la ley. 
El código civil del Ecuador habla en uno de sus tantos artículos sobre la reparación de daño y para ser exactos en el Art. 2229, reza que "Por regla general todo daño que pueda imputarse a malicia o negligencia de otra persona debe ser reparado por ésta"(EDICIONES LEGALES, 2013); por lo que deberemos entender que muchos de estos casos de responsabilidad civil solicitan reparación del daño mediante compensaciones monetarias, siempre que se haya declarado por el demandante la inobservancia, impericia, imprudencia o negligencia de los actos de salud. Estas compensaciones monetarias suelen ser justificadas por el demandante como gasto de "curación, compensación económica por el tiempo que el paciente dejó de trabajar, así como otros gastos en que incurrió él o su familia para su curación o rehabilitación" (Guerrero, 2020)

Así mismo, el código civil invita a revisar lo que respecta al "Art. 2214.- El que ha cometido un delito o cuasidelito que ha inferido daño a otro, está obligado a la indemnización; sin perjuicio de la pena que le impongan las leyes por el delito o cuasidelito" (EDICIONES LEGALES, 2013), he aquí otra norma que puede representar compensaciones para la víctima, pero a la vez también se encuentra entrelazada con lo penal, ya que del delito puede tomar 2 caminos, un delito con dolo que puede llevar a sufrir sanciones o a su vez un delito por culpa donde va a tener que resarcir el daño causado.

Por su parte, el COAJ indica en su primer artículo que "Art. 1.- Objeto. Este Código regula el ejercicio de la función administrativa de los organismos que conforman el sector público" (Barrezueta, 2017). En este sentido tanto el Ministerio de Salud, Comisarías de Salud o la Agencia de Aseguramiento de la Calidad de los Servicios de Salud y Medicina Prepagada (ACESS), son los encargados de regular actos irregulares en el ámbito de la salud, por lo que basta una denuncia o simplemente por oficio, para que se dé un proceso de investigación.

Dentro del proceso que se lleva a cabo debe demostrarse por parte del ente administrativo la infracción existente, así como la responsabilidad del supuesto infractor; 
Hernán Santiago Segarra-Cevallos; María Auxiliadora Santacruz-Vélez; Eduardo Xavier León-Micheli;

Marcelo Jorge López-Mesa

sin embargo dentro de este mismo proceso existe también "el derecho del presunto infractor a defenderse, presentando pruebas de descargo que lo enerven de responsabilidad o justifiquen su accionar" (Guerrero, 2020).

Pero para que esto concurra debe estar presentes tres entidades básicas, siendo la primera la existencia del daño como tal, porque sin ello no se configura la responsabilidad de reparación; el segundo un infractor (personal de salud), que dentro de su actuar (acción u omisión) debió haber concurrido en inobservancia, impericia, imprudencia 0 negligencia; y el tercero el nexo causal que es el hecho que une la existencia del daño con el actuar del infractor; estas tres entidades son importantes para poder hablar de responsabilidad.

Este proceso tiene por resultado acciones administrativas que van desde "multas, suspensión del permiso o licencia, suspensión del ejercicio profesional, decomiso o clausura parcial, temporal o definitiva del establecimiento; sanciones que deberán ser aplicadas de forma proporcional de acuerdo a la gravedad de la infracción cometida"(Guerrero, 2020).

Súmese lo que dice el Código Orgánico Administrativo en lo referente a las infracciones de los actos de salud. Art. 202.- Constituye infracción en el ejercicio de las profesiones de salud, todo acto individual e intransferible, no justificado, que genere daño en el paciente y sea resultado de:

a) Inobservancia, en el cumplimiento de las normas;

b) Impericia, en la actuación del profesional de la salud con falta total o parcial de conocimientos técnicos o experiencia;

c) Imprudencia, en la actuación del profesional de la salud con omisión del cuidado o diligencia exigible; $y$,

d) Negligencia, en la actuación del profesional de la salud con omisión o demora injustificada en su obligación profesional. (COAJ, artículo 202). 
En fin, la salud al ser un derecho que está garantizado por el Estado, hace que este tenga la facultad de normar, vigilar, controlar y sancionar a personal e instituciones prestadoras del servicio de salud por los actos de salud que van contra este derecho fundamental.

\section{Los eximentes de responsabilidad por actos de salud}

Se iniciará diciendo que los eximentes de responsabilidad son en general la posibilidad que tiene el demandado para configurar su defensa, es decir es la "causal que impide imputar determinado daño a una persona, haciendo improcedente, en consecuencia, la declaratoria de responsabilidad" (Patiño, 2011) y cuya característica se basarían en atacar cualquiera de los elementos (daño, imputación, fundamentos) que se presentan dentro un juicio de responsabilidad.

Ahora, también es importante rescatar que ante regímenes subjetivos u objetivos de responsabilidad, es el demandado el que tiene que probar "ausencia de falla, la inexistencia del nexo causal, o probando causa extraña"(Patiño, 2011).

Ahora bien, la balanza del juicio de responsabilidad debe ser por lo más apegado a la verdad, tanto para la parte demandante, como para la demandada, esto sin "asumir al sistema de salud como el enemigo a vencer" (Jaimes, 2021), ya que las diferentes circunstancias del día a día, muchos de estos sistemas de salud se encuentran sin salidas que eviten pisar la delgada línea de responsabilidad por actos de salud.

\section{Hechos internos}

Los hechos internos, como causa exonerativa de responsabilidad, se describen como "aquellas situaciones que devienen de manera directa de la actuación del sistema de salud" (Jaimes, 2021), pero claro está que no todo daño tiene que ser reparado, ya que sería por el mero hecho fenomenológico. 
Por ello, al existir un daño (tras una atención de salud), lo siguiente que se debe formular de manera inmediata, es cuál de las circunstancias o hechos de manera directa causo y tuvo dentro de sus características y particularidades el porte para crear dicho daño, sin tener relación alguna con algún hecho externo.

Por poner un ejemplo, la falta de asepsia y antisepsia al colocar un catéter venoso central (mala praxis) en un paciente con diagnóstico de choque, cualquiera que sea su causa (hecho externo), entraría a ser considerado uno de los hechos internos posibles, ya que al consumarse actos de atención dentro de un sistema de salud, que van en contra de lo que estipula las leyes, normativas, protocolos con respecto al derecho de la salud, se generarían los hechos internos que pondrían al personal de salud dentro de un juicio de responsabilidad por actos de salud.

\section{Hechos externos}

Los hechos externos, se deben entender como los escenarios donde ocurren circunstancias ajenas a las acciones del presunto agraviado, que al no poderles relacionar con el mismo, pueden ser utilizados como eximentes de responsabilidad, más aún en el tema por actos de salud.

Pero hay que tener también en claro que los hechos externos no son eximentes de responsabilidad -al menos no per se- (Jaimes, 2021); es decir, por sí mismos; por lo que no sólo deben existir u ocurrir; sino también el hecho externo "debe ser imprevisible, irresistible, exclusivo y determinante" (Jaimes, 2021), para con ello lograr una situación tan favorable, que puedan ser usados como eximentes de responsabilidad por actos de salud.

\section{Presupuestos de los hechos externos}

Los hechos externos deben cumplir con ciertas características que nombramos en el punto anterior, pero que en este apartado los trataremos uno a uno. Se empezará por la imprevisibilidad, que no es más que la situación donde un ser humano no puede avizorar 
con anterioridad de tiempo los acontecimientos que ocurren durante la realización de un acto de salud, es decir le es imposible tomar medidas para evitar que se origine algún tipo de daño o lesión.

La segunda característica nombrada es la irresistibilidad, cuya peculiaridad está en "la imposibilidad de contener parcial o totalmente los efectos negativos de una situación en concreto" (Jaimes, 2021), que indistintamente pueden presentarse, así como no, ante la existencia de previsibilidad. Es por eso, que, con el avance de la ciencia, tecnología, las posibilidades de irresistibilidad e imprevisibilidad van disminuyendo, haciendo que los sucesos cada vez sean más prevenibles y por ende la formulación de un hecho externo se va desvaneciendo paulatinamente.

Sin embargo, existe un resultado que configuraría un eximente de responsabilidad y es el que se prevea acciones en hechos que son prevenibles, así como también se despliegue acciones en pos de contener los efectos negativos de un suceso, lo que constituiría como un eximente de responsabilidad.

La tercera característica es lo exclusivo, que para fines de entendimiento hace referencia a que un hecho externo se vuelve exclusivo cuando se da una imprudente exposición por parte del agraviado al hecho dañino, es decir tendrá características de eximente de responsabilidad siempre y cuando este excluya o tenga la fuerza para excluir a cualquier otro hecho en la producción del daño.

Y por último, una característica no menos importante es la de ser determinante y la cual claramente puede hacer referencia a la acción única y precisa para generar daño en su sentido fenomenológico.

\section{Clases}

Al hablar de causales que eximen de responsabilidad por hechos externos, podemos enumera los siguientes: 1) Hecho exclusivo y determinante de un tercero, 2) hecho 
exclusivo y determinante de una víctima, 3) y 4) hecho exclusivo y determinante de una Fuerza mayor o de un Caso fortuito, todos ellos con características específicas y únicas que les dan esa potestad de ser utilizados ante juicios de responsabilidad y que los revisaremos a continuación.

En este punto, sólo se abordará lo concerniente a la fuerza mayor y caso fortuito, entendiendo como tal, el evento que es imposible de resistir, o como lo sostiene la Corte Nacional de Justicia del Ecuador en diferentes fallos judiciales en los que indica que la fuerza mayor es "una fuerza irresistible", cuyos elementos que la conforman son la irresistibilidad e imprevisibilidad, que permitirían la exoneración completa del demandado, esto siendo justificado como una causa extraña. A la fuerza mayor se le relaciona con eventos naturales como "terremotos, tormentas, actividades volcánicas entre otros muchos" .(Jaimes, 2021) y quizá por estas peculiaridades de no poder presentársele oposición alguna, es capaz de romper el nexo causal y de esta manera se vuelve un eximente de responsabilidad, además se le considera por los órganos que administran justicia como en acontecer externo a la actividad generadora del daño En el derecho anglosajón al caso fortuito se le conoce como "un hecho de Dios"(JALEEL, 2021), en el caso de la Corte Nacional de Justicia del Ecuador se le conoce como "un acontecimiento imprevisible" (JALEEL, 2021), pero quizá el concepto que para mi entender es mucho más sublime es el siguiente, ya que nos permite reconocer las características el mismo, entonces diremos que caso fortuito es "un suceso que el individuo genera de manera involuntaria $y$, por tanto, no se espera que cumpla con determinadas obligaciones" (Jaimes, 2021), esto siempre y cuando sea imprevisible, y por lo cual no podría resistirse.

Sin embargo, es importante señalar en este punto que en la legislación ecuatoriana, el Código Civil, en su artículo 30 nos establece en lo siguiente: "Se llama fuerza mayor o caso fortuito el imprevisto al que no es posible resistir"(Código Civil, 2016), con lo que se deja ver que en nuestra país su normativa no hace diferencia entre fuerza mayor o caso 
fortuito, pero en otros países su legislatura sí, considerando al caso fortuito como una situación interna generadora del daño.

En fin, tanto el caso fortuito como la fuerza mayor parten de una realidad basada en la imprevisibilidad y la irresistibilidad, que a su vez crean un principio, el principio "que nadie está obligado a lo imposible" (Jaimes, 2019).

\section{CONCLUSIONES}

Los actos de salud están relacionados a la acción u omisión de hechos al momento de realizar la atención de un paciente, ya que por el simple hecho que su salud se vea disminuida por factor sea externo o interno propio de él, pone al personal de salud en una posición de resultado de medios, ya que se sus acciones deberán de ir acorde a las normas, leyes, manuales y protocolos dispuestos o creados para cumplir con los cuidados de las diferentes patologías, que por años en la continua existencia del hombre se han ido creando.

La evolución del hombre, del medio que lo rodea, la tecnología, la ciencia han hecho que aparezcan tratamientos que para el común de los mortales es sanadora, pero así mismo ha hecho que cuando no tiene el mismo resultado de sanar, sino de no curar, de enfermar hacen que sean vistos como eventos culposos por el resto de actores (familia, abogados, jueces) que perciben dicha situación.

Pero al mirar más a fondo, quizá con una claridad ayudada por ciertos conocimientos, pruebas y posibles eximentes de responsabilidad, hace que el personal de salud pueda expresar que sus actos, nunca estuvieron dirigidos a producir el daño y por tanto no son responsables de sucesos que en suma llevaron a la producción de un daño. El simple hecho de cumplir con las normas, leyes, guías, protocolos o cualquier tipo de acción validada en la atención de salud, debería ser considerada como un eximente de responsabilidad. 
Hernán Santiago Segarra-Cevallos; María Auxiliadora Santacruz-Vélez; Eduardo Xavier León-Micheli;

Marcelo Jorge López-Mesa

Por lo que, al hablar de responsabilidad por actos de salud al presentarse IAAS en pacientes con COVID 19, es más con otras patologías, deberá entenderse como un factor imposible de erradicar, imposible de soportar por cualquier lado que se mire y que el personal de salud estaría de esta manera liberado de responsabilidad tanto por hechos internos y/o hechos externos, dejando así claro un tema que quizá en poco tiempo sea causa de posible denuncias de mala praxis médica o casos de responsabilidad por actos de salud.

\section{REFERENCIAS CONSULTADAS}

Barrezueta, P. (2017). Código Orgánico Administrativo COA. 31, 1-58.

Barroso Peña, Y., Avila Balmaseda, Y., Rodríguez Bencomo, D. de J., \& Rodríguez Romero, A. (2020). Características clínico epidemiológicas de la COVID 19. Arch. Méd. Camaguey, 14(3), 0-0.

Código Civil, C. de L. y C. (2016). Código Civil Normativa vigente. 2005, 1-209. https://n9.cl/x5ko

Douedi, S., \& Miskoff, J. (2020). Novel coronavirus 2019 (COVID-19). Medicine, 99(19), e20207. https://doi.org/10.1097/md.0000000000020207

Ediciones Legales. (2013). Código civil. Codigo Civil, O(2005), 1-151.

García Bacallao, L. (2020). Revista habanera de ciencias médicas. Revista Habanera de Ciencias Médicas, 9(2), 156-166.

González Cano, J. A., Noriega Verdugo, D. D., Escariz Borrego, L. I., \& Mederos Molina, K. (2019). Incidencia de factores de riesgo en infecciones asociadas a la atención de salud en pacientes críticos. Revista San Gregorio, 31, 110. https://doi.org/10.36097/rsan.v0i31.862

Guerrero, A. (2020). Tipos De Responsabilidad Profesional Médica. Derecho - Ecuador, $1-4$. 
Hernán Santiago Segarra-Cevallos; María Auxiliadora Santacruz-Vélez; Eduardo Xavier León-Micheli; Marcelo Jorge López-Mesa

Jaime, A. E. (2019). Derecho de daños: responsabilidad extracontractual del estado. Cúcuta, Colombia: Jaimes Abogados.

Jaimes, A. E. (2021). Tratado de responsabilidad estatal por actos de salud. Cúcuta, Colombia: Jaimes Abogados S.A.S.

Jaleel, V. H. A. (2021). Interpretación de fuerza mayor o caso fortuito en las obligaciones en tiempos de COVID Ecuador. 3(2), 6.

Maguiña Vargas, C., Gastelo Acosta, R., \& Tequen Bernilla, A. (2020). El nuevo Coronavirus y la pandemia del Covid-19. Revista Medica Herediana, 31(2), 125-131. https://doi.org/10.20453/rmh.v31i2.3776

Maracaibo, H. U. De, \& Castellano, G. M. J. (2020a). Infecciones asociadas a la atención en salud. 5, 48-61.

Maracaibo, H. U. De, \& Castellano, G. M. J. (2020b). Introducción. 5, 48-61.

Mayssara A. Abo Hassanin Supervised, A. (2014). Responsabilidad civil médica por infecciones asociadas a la atención en salud (IAAS). In Paper Knowledge. Toward a Media History of Documents.

Ministerio de Salud Pública. (2019). Subsistema de vigilancia epidemiológica para las Infecciones Asociadas a la Atención en Salud. Subsistema de Vigilancia Epidemiologica (SIVE), 1-6. https://n9.cl/vnglt

Montero, B. C., Zeledón Pórez, M., Vesalio, A., Edgar, G., \& Solera, C. (1973). Infección Intra -Hospitalaria. 440, 39-51.

OPS. (2021). Actualización Epidemiológica Enfermedad por coronavirus Tabla de Contenido. Organización Panamericana de La Salud, 26. https://n9.cl/jpu8h

Organization, W. H. (2005). Reto Mundial en Pro de la Seguridad del Paciente. World Alliance for Patient Safety, 53(9), 1689-1699.

Patiño, H. (2011). Las causales exonerativas de la responsabilidad. Revista de Derecho Privado, Vol.20, pp.371-398. 


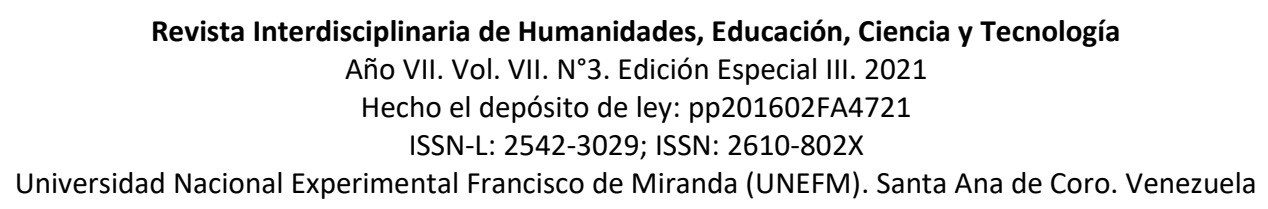

Hernán Santiago Segarra-Cevallos; María Auxiliadora Santacruz-Vélez; Eduardo Xavier León-Micheli;

Marcelo Jorge López-Mesa

Tang D, Comish P, K. R. (2021). Las características de la enfermedad COVID-19. Las Características de La Enfermedad COVID-19, 77-82. https://doi.org/https://doi.org/10.1371/journal.ppat.1008536

Unahalekhaka, A. (2011). Epidemiología de las infecciones asociadas a la atención en salud. Epidemiologia de Las Infecciones Asociadas a La Atencion de Salud, 29-44.

(C2021 por los autores. Este artículo es de acceso abierto y distribuido según los términos y condiciones de la licencia Creative Commons Atribución-NoComercial-Compartirlgual 4.0 Internacional (CC BY-NC-SA 4.0)

(https://creativecommons.org/licenses/by-nc-sa/4.0/). 